\title{
Effect of Relative Air Humidity and High Temperature on the Physiological and Anatomical Responses of Two Rhododendron Cultivars
}

\author{
Wenjie Ma, Wen Liang, and Bing Zhao' \\ College of Landscape Architecture and Arts, Northwest A\&F University, \\ Yangling, 712100, People's Republic of China
}

Additional index words. heat stress, vapor pressure deficit, photosynthesis, stomata function, morphological performance

\begin{abstract}
The effects of different relative air humidity (RH) levels under high temperature and accompanying vapor pressure deficits (VPDs) on the physiology, photosynthesis, and anatomy of Rhododendron need to be better understood to help in reducing damage to leaves caused by high temperature. In this study, two Rhododendron cultivars were exposed at $45 \%, 55 \%, 65 \%, 75 \%$, and $85 \%$ RH to a treatment of constant temperature at $38{ }^{\circ} \mathrm{C}$ for 14 days, resulting in a VPD of 3.64, 2.98, 2.32, 1.66, and $0.99 \mathrm{kPa}$, respectively. The results showed the least reduction of the net photosynthetic rate $\left(P_{n}\right)$ under $75 \%$ RH treatment in $R$. 'Fen Zhenzhu' (decreased by $79.8 \%$ ), and under the $85 \%$ RH treatment in $R$. 'Zhuangyuan Hong' (decreased by $75.4 \%$ ). The decline in relative water content (RWC) was less under the $75 \%$ and $85 \%$ RH treatments, and electrolyte leakage showed a slight decrease under the $75 \%$ RH treatment in the two Rhododendron cultivars. The appearance of the two cultivars under greater RH showed less damage, probably because plants can avoid damage by increasing total chlorophyll content, decreasing stomatal area, stomatal density, and opened stomata ratio, enhancing enzymatic activity and osmoregulation substances, and improving leaf structure. The findings show that greater RH can alleviate damage caused by heat stress and improve thermostability.
\end{abstract}

As plants are sessile organisms that cannot avoid heat, they often encounter harsh heat stress (Wang et al., 2018). Heat stress can impose different metabolic and physical challenges on almost all aspects of plant development, growth, reproduction, and yield (Zhang et al., 2016). In ornamental plants, high temperature can have a negative influence on their appearance and their ornamental value (Shen et al., 2017). The ability of plants to respond and successfully adjust to heat stress treatment is referred to as thermotolerance (Ohama et al., 2017). Plants can improve or acquire thermotolerance in several ways. Currently, the known pathways to enhance thermotolerance of plants include breeding of heat-tolerant cultivars (Yan et al., 2010), heat acclimation (Mueller et al., 2015), spraying exogenous substances such as salicylic acid and calcium solution (Shen et al., 2016), inoculation of fungus (Martin and Stutz, 2004), and improving cultivation and management measures, such as light intensity and RH (Lu et al., 2017; Marchin et al., 2016).

$\mathrm{RH}$ is the ratio of the amount of water vapor in the air relative to the amount of water

Received for publication 20 Feb. 2019. Accepted for publication 29 Mar. 2019.

We are all grateful for the Natural Science Foundation of Shaanxi Province of China (2018JQ3060) and the Special Foundation of Basic Research of Northwest A\&F University (Z109021703).

${ }^{1}$ Corresponding author. E-mail: bingzhao@nwsuaf. edu.cn. vapor that would be present at saturation, which also influences many life processes such as stomatal function, transpiration, and accumulation of phenolics (Fanourakis et al., 2016). High RH not only exists in natural environment such as tropical rain forests (Haupt et al., 2011) and Denmark (New at el., 2002) but also will be increased because of more frequent precipitations in the future in northern latitudes predicted by climate change modeling estimations (Tullus et al., 2012). Under mild temperatures $\left(18\right.$ to $\left.22{ }^{\circ} \mathrm{C}\right)$, high RH-grown roses $(\mathrm{RH} \geq 85 \%)$ showed severer symptoms of leaf damage (Fanourakis et al., 2015). The effect of both RH and variation in temperature is combined by the VPD, which indicates the change between the saturated vapor pressure (inside the stomatal cavity) and actual air vapor pressure (surrounding environment) (Fanourakis et al., 2016). Research has shown that VPD not only has a direct effect on stomatal conductance $\left(g_{\mathrm{s}}\right)$, photosynthesis, and water transport (Sinclair et al., 2007) but also affects plant temperature via transpiration. Greater VPD reduced leaf temperature by stimulating transpiration (Fanourakis et al.,2015). However, there are few studies on the changes in the performance and physiology of plants subjected to various VPD levels with different $\mathrm{RH}$ levels under heat stress, whereas there are several studies with regard to the optimal growth temperature (Arve et al., 2017; Perdomo et al., 2016).

Rhododendron has long been used in urban landscaping, where it is highly valued for its long-lasting, bright, and colorful flowers. However, many Rhododendron cultivars are sensitive to heat because of genetic factors and are more affected in summer (Shen et al., 2017). Thus, it is necessary to explore the possibility of improving the heat tolerance of Rhododendron by modifying RH. In the present study, photosynthesis, cell membrane thermostability, osmoregulation substances, reactive oxygen species (ROS) scavenging ability, and anatomy of leaves were investigated in the two Rhododendron cultivars. The experiments were conducted in an artificial climate chamber, which allowed plants to be subjected to controlled temperature and $\mathrm{RH}$ The effects of different RH levels under high temperature and accompanying VPDs on the physiology, photosynthesis, and anatomy of Rhododendron need to be better understood to help reduce damage to leaves caused by high temperature. The results of these experiments indicate a major response in plants directly associated with different $\mathrm{RH}$ levels under heat stress and can contribute to the further cultivation of Rhododendron in summer.

\section{Materials and Methods}

Plant materials and treatments. Threeyear-old, healthy, and uniformly grown cuttings of two Rhododendron cultivars, Rhododendron 'Fen Zhenzhu' and Rhododendron 'Zhuangyuan Hong', were used as experimental materials. They were all purchased from Jiashan, Zhejiang Province, in Nov. 2017 and exhibit a certain tolerance to high temperature (Shen et al., 2017). They were grown in doublecolor plastic pots (brown outside and black inside), which were $12 \mathrm{~cm}$ high with a $16-\mathrm{cm}$ diameter at the top and a $10-\mathrm{cm}$ diameter at the bottom containing a mixture of peat and pine needle mulch $(\mathrm{v} / \mathrm{v}=1: 2)$ in a greenhouse located in Yangling, Shaanxi Province. Then, 54 pots of each Rhododendron cultivar were allocated to different BIC-400 artificial climate chambers (Boxun, Shanghai, China) at constant temperature treatments of $22{ }^{\circ} \mathrm{C}$ and $85 \% \mathrm{RH}$ (resulting in a VPD of $0.40 \mathrm{kPa}$ ), with a photoperiod of $14 \mathrm{~h}$ of day and $10 \mathrm{~h}$ of night. The light level was $150 \mu \mathrm{mol} \cdot \mathrm{m}^{-2} \cdot \mathrm{s}^{-1}$ for $7 \mathrm{~d}$ for acclimation. Thereafter, nine pots of each cultivar were transferred simultaneously to different artificial climate chambers at a constant temperature treatment of $38^{\circ} \mathrm{C}$ for $14 \mathrm{~d}$ and various $\mathrm{RH}, 45 \%, 55 \%, 65 \%, 75 \%$, and $85 \%$, resulting in a VPD of $3.64,2.98,2.32$, 1.66 , and $0.99 \mathrm{kPa}$, respectively. Another nine pots were maintained at $22{ }^{\circ} \mathrm{C}$ and $85 \% \mathrm{RH}$ throughout as the control (CK). To diminish the positional effects, the pots in the chambers were interchanged randomly twice a day. The plants were managed regularly and watered twice a day to avoid drought during the experiment. The plants were sampled after $14 \mathrm{~d}$.

VPD $(\mathrm{kPa})$ was calculated by temperature and RH (Howell and Dusek, 1995): VPD = $(1-\mathrm{RH}) \times 0.611 \times \mathrm{e}^{[17.27 \times \mathrm{T} /(\mathrm{T}+237.3)]}$, where $\mathrm{T}$ represents temperature.

Measurement of gas exchange characteristics. After the treatments, the gas exchange 
parameter was measured on the third fully expanded leaf, which was fully-grown before the onset of the experiment. A portable photosynthesis analysis system Li-6400 XT (LICOR Biosciences, Lincoln, NE) was used to determine the $\mathrm{P}_{\mathrm{n}}, g_{\mathrm{s}}$, transpiration rate $\left(\mathrm{T}_{\mathrm{r}}\right)$, and intercellular $\mathrm{CO}_{2}$ concentration $\left(\mathrm{C}_{\mathrm{i}}\right)$ between 8:00 AM and 10:00 AM. The system maintained the measurement conditions of $6 \mathrm{~cm}^{2}$ leaf area and $500 \mu \mathrm{mol} \cdot \mathrm{s}^{-1}$ flow rate to the sample cell.

Measurement of anatomy parameter. Sections of leaves, obtained by the methods reported by Fanourakis et al. (2015), $3 \mathrm{~mm} \times 3 \mathrm{~mm}$ in size, were collected from the plants between 8:00 $\mathrm{AM}$ and 10:00 $\mathrm{AM}$ after the treatment period of $14 \mathrm{~d}$. The samples were fixed in $4 \%$ glutaraldehyde at $4{ }^{\circ} \mathrm{C}$ for $24 \mathrm{~h}$. After fixation, the samples were cleaned four times with $0.1 \mathrm{M}$ phosphate buffer ( $\mathrm{pH}$ 6.8) for $15 \mathrm{~min}$, then dehydrated consecutively for $15 \mathrm{~min}$ with $30 \%, 50 \%$, $70 \%, 80 \%$, and $90 \%(\mathrm{v} / \mathrm{v})$ ethanol and for $30 \mathrm{~min}$ with $100 \%(\mathrm{v} / \mathrm{v})$ ethanol, and finally moved to isoamyl acetate. The samples were then dewatered with a K-850 $\mathrm{CO}_{2}$ critical point dryer (Quorum, Laughton, UK), and mounted on stubs with colloidal silver, sputter-coated with gold using an E-1045 ion coater (Hitachi, Tokyo, Japan). Finally, samples were observed and photographed with a JSM-6360LV scanning electron microscope (JEOL, Tokyo, Japan) at $5 \mathrm{kV}$. Thickness of leaves, cuticle, palisade tissue, and midrib were measured and calculated from 15 observations. Stomatal density and ratio of opened stomata (the ratio of the average number of open stomata and the average total number of stomata under eight views) were calculated by eight views of scanning electron microscope observations. Fifteen opened stomata lengths and widths were averaged to estimate the stomatal area according to the ellipse area formula: $1 / 4 \times$ (length $\times$ width $\times \pi$ ) (Chen et al., 2014).

Measurement of chlorophyll and RWC. The chlorophyll content of leaves was measured according to Hiscox and Israelstam (1979). To summarize, $0.1 \mathrm{~g}$ of fresh leaves were soaked in $25 \mathrm{~mL}$ of $80 \%(\mathrm{v} / \mathrm{v})$ acetone, and then the extract of the samples was measured at 645 and $663 \mathrm{~nm}$ by GENESYS $10 \mathrm{~S}$ ultraviolet-Vis spectrophotometer (Thermo Fisher Scientific, Waltham, MA) after 24-h dark treatment. The chlorophyll content was calculated by the following formulae:

$$
\begin{aligned}
\mathrm{Chl} \mathrm{a}(\mathrm{mg} / \mathrm{g} \mathrm{FW})= & \left(12.72 \times \mathrm{A}_{663}\right. \\
& \left.-2.59 \times \mathrm{A}_{645}\right) \times \mathrm{V} / \mathrm{W}
\end{aligned}
$$

$\mathrm{Chl} \mathrm{b}(\mathrm{mg} / \mathrm{g} \mathrm{FW})=\left(22.88 \times \mathrm{A}_{645}\right.$

$$
\left.-4.67 \times \mathrm{A}_{663}\right) \times \mathrm{V} / \mathrm{W}
$$

Chl total $(\mathrm{mg} / \mathrm{g} \mathrm{FW})=\left(20.2 \times \mathrm{A}_{645}\right.$

$$
\left.+8.02 \times \mathrm{A}_{663}\right) \times \mathrm{V} / \mathrm{W}
$$

where $\mathrm{A}_{645}$ and $\mathrm{A}_{663}$ are the absorbance of the extract solution at 645 and $663 \mathrm{~nm}$, respectively, $\mathrm{V}$ represents the supernatant volume, W represents the fresh weight, and FW represents the fresh weight of the leaf.

RWC (\%) was measured to determine leaf water status between 8:00 $\mathrm{AM}$ and 10:00 AM, and it was calculated according to Barrs and Weatherley (1962): RWC $=(\mathrm{FW}-\mathrm{DW}) /$ $(\mathrm{SW}-\mathrm{DW}) \times 100$, in which FW represents the leaf fresh weight, DW represents the dry weight of leaves after drying at $85^{\circ} \mathrm{C}$ for $2 \mathrm{~d}$, and SW represents the turgid weight of leaves after soaking in water for $4 \mathrm{~h}$ at $25^{\circ} \mathrm{C}$.

Electrolyte leakage assay and measurement of malondialdehyde (MDA) and hydrogen peroxide $\left(\mathrm{H}_{2} \mathrm{O}_{2}\right)$. Samples of fresh leaves $(0.1 \mathrm{~g})$ from the different treatments were cleaned in double-distilled water, transferred to $25 \mathrm{~mL}$ of double-distilled water, and pumped in vacuum for $30 \mathrm{~min}$. The electrical conductivity (EC) was confirmed by DDSJ-308A conductivity bridge (Leici, Shanghai, China) after $2 \mathrm{~h}$ (EC1). Then, the samples were boiled for $20 \mathrm{~min}$ and the EC was recorded (EC2) after samples were cooled to $25^{\circ} \mathrm{C}$. The electrolyte leakage was determined as per the protocol of Palta et al. (1977) and calculated according to EC1 / EC2 $\times 100 \%$.

MDA was measured by the method reported by Zhou and Leul (1998) with slight modifications. The crude extract of leaves (2 $\mathrm{mL}$ ) stored in liquid nitrogen was ground in 10 $\mathrm{mL}$ of $10 \%$ trichloroacetic acid. The mixture was centrifuged at $4000 g_{n}$ for $10 \mathrm{~min}$, and then $2 \mathrm{~mL}$ supernatant was extracted and mixed with $2 \mathrm{~mL} 0.6 \%$ thiobarbituric acid and heated in boiling water for $15 \mathrm{~min}$. After centrifugation at $4000 g_{\mathrm{n}}$ for $10 \mathrm{~min}$, the absorbance of the homogenate was recorded at $532 \mathrm{~nm}, 600$ $\mathrm{nm}$, and $450 \mathrm{~nm}$ with a spectrophotometer ( $\mathrm{Yu}$ et al., 2016). The MDA content was calculated using the formula:

$$
\begin{aligned}
\operatorname{MDA}\left(\mu \mathrm{mol} \cdot \mathrm{g}^{-1}\right)= & {\left[6.45 \times\left(\mathrm{A}_{532}-\mathrm{A}_{600}\right)\right.} \\
& \left.-0.56 \times \mathrm{A}_{450}\right] \times \mathrm{V} / \mathrm{W}
\end{aligned}
$$

where $\mathrm{A}_{532}, \mathrm{~A}_{600}$, and $\mathrm{A}_{450}$ are the absorbance of the extract solution at 532,600, and $450 \mathrm{~nm}$, respectively, V represents the supernatant volume, and $\mathrm{W}$ represents the weight.

The $\mathrm{H}_{2} \mathrm{O}_{2}$ content in $0.1 \mathrm{~g}$ of the samples was measured according to the hydrogen peroxide assay kit (Jiancheng, Nanjing, China). Absorbance of the homogenate was measured at $405 \mathrm{~nm}$ with a spectrophotometer.

Osmoregulation substances analyses. Total soluble sugars were measured according to the method of Irigoyen et al. (1992) with slight modifications. The extract of $0.1 \mathrm{~g}$ of the samples in different treatments in $25 \mathrm{~mL}$ of double-distilled water was centrifuged at $3500 g_{\mathrm{n}}$ for $10 \mathrm{~min}$. Then, $2 \mathrm{~mL}$ of supernatant, $0.5 \mathrm{~mL}$ of anthrone reagent, and $5 \mathrm{~mL}$ of concentrated sulfuric acid were mixed and boiled for $1 \mathrm{~min}$. After cooling, absorbance of the mixture was measured at 630 $\mathrm{nm}$ using a spectrophotometer. The results were calculated using a standard curve of glucose.

The proline was determined by using the acid-ninhydrin method according to Bates et al. (1973). The sample $(0.1 \mathrm{~g})$ was soaked in $5 \mathrm{~mL}$ of $3 \%$ aqueous sulfosalicylic acid and the extract was boiled for $10 \mathrm{~min}$. The supernatant $(2 \mathrm{~mL})$ was treated with an equal volume of acid-ninhydrin and glacial acetic acid for $30 \mathrm{~min}$ in a $100{ }^{\circ} \mathrm{C}$ water bath, and then $5 \mathrm{~mL}$ of toluene was added. Absorbance of the toluene layer was measured at $520 \mathrm{~nm}$ with a spectrophotometer. Proline content was calculated using a standard curve with known concentrations of proline.

The total soluble protein content in $0.1 \mathrm{~g}$ of the samples was measured according to the total soluble protein assay kit (Jiancheng). Absorbance of the extract was measured at $595 \mathrm{~nm}$.

Assay of antioxidant enzyme activities. After grinding with liquid nitrogen, $0.1 \mathrm{~g}$ of the sample was suspended into $2 \mathrm{~mL}$ of icecold PBS buffer ( $50 \mathrm{~mm}, \mathrm{pH} 7.8$ ). The mixture was centrifuged at $4{ }^{\circ} \mathrm{C}$ and $12,000 g_{n}$ for 20 min, and the resulting supernatants were used to determine the activities of superoxide dismutase (SOD), peroxidase (POD), and catalase (CAT) (Zhang et al., 2012).

Activity of SOD was measured in accordance with Giannopolitis and Ries (1977). The $3-\mathrm{mL}$ reaction solution containing $13 \mathrm{~mm}$ methionine, $75 \mathrm{nM}$ ethylenediaminetetraacetic acid, $50 \mu \mathrm{M}$ NBT, $1.3 \mu \mathrm{M}$ riboflavin, $50 \mathrm{~mm}$ PBS buffer ( $\mathrm{pH} 7.8$ ), and $50 \mu \mathrm{L}$ of enzyme extract was irradiated under a light of 50 $\mu \mathrm{mol} \cdot \mathrm{m}^{2} \cdot \mathrm{s}^{-1}$ for $20 \mathrm{~min}$. The absorbance was measured at $560 \mathrm{~nm}$. One unit of SOD activity was defined as the amount of enzyme that can cause a $50 \%$ inhibition on the rate of nitroblue tetrazolium reduction (Zhang et al., 2012).

Activity of POD was analyzed as reported by Chance and Maehly (1955) with slight modifications, and the absorbance was measured at $470 \mathrm{~nm}$. The assay reaction solution to confirm POD activity contained $50 \mathrm{~mm}$ PBS buffer ( $\mathrm{pH} 7.8$ ), $30 \%$ (v/v) $\mathrm{H}_{2} \mathrm{O}_{2}, 100 \%$ guaiacol solution, and $50 \mu \mathrm{L}$ of enzyme extract. In addition, a reaction mixture, which contained $22.5 \mu \mathrm{L}$ of enzyme extract, $100 \mathrm{~mm}$ phosphate buffer ( $\mathrm{pH} 7.8$ ), and $10 \mathrm{~mm} \mathrm{H}_{2} \mathrm{O}_{2}$, was used to assay the activity of CAT at $240 \mathrm{~nm}$ via the decompounding of $\mathrm{H}_{2} \mathrm{O}_{2}\left(\varepsilon=40 \mathrm{M}^{-1} \cdot \mathrm{cm}^{-1}\right)$ (Pereira et al., 2002; Zhang et al., 2012). One unit of activity for POD and CAT was defined as the amount of enzyme that inhibited $1 \%$ of degraded $1 \mu \mathrm{M}$ guaiacol radical and degraded $1 \mathrm{mmol} \mathrm{H}_{2} \mathrm{O}_{2}$ per minute, respectively.

Experimental design and statistical analysis. The experiment was arranged in a completely randomized design with nine plants in each treatment and three replicates. Data were analyzed by SPSS 19.0 (IBM Corp, Armonk, NY), and Duncan's multiple range test was used to compare treatments when analysis of variance showed obvious changes between means at $P \leq 0.05$. Pictures were prepared using Photoshop CS4 (Adobe Inc., San Jose, CA) and OriginPro 9.0 (OriginLab Corp, Northampton, MA).

\section{Results}

Changes in appearance, RWC, and electrolyte of the two Rhododendron 

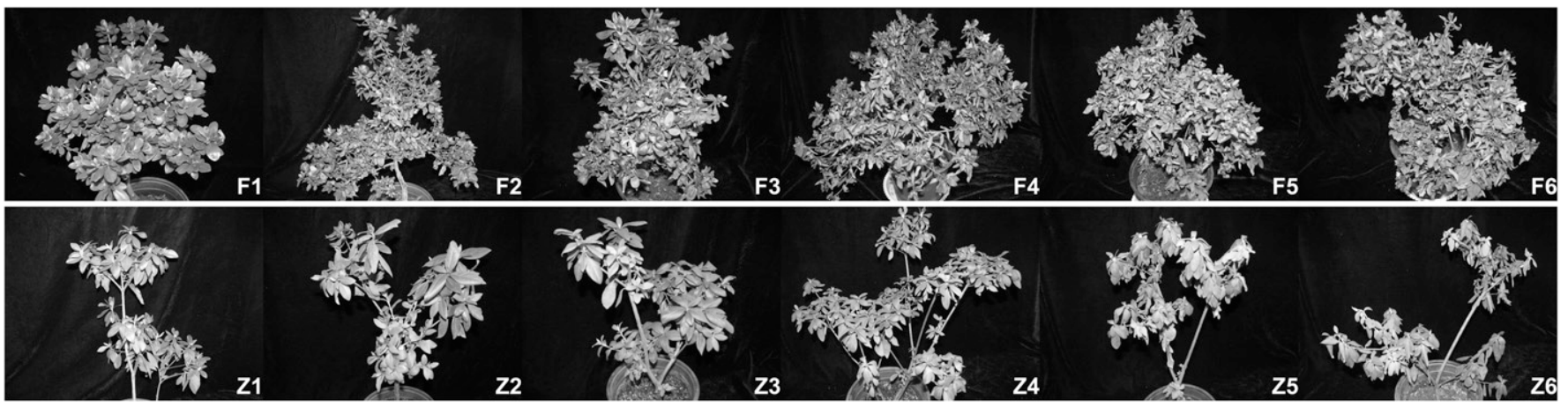

Fig. 1. Appearance of two Rhododendron cultivars under different VPD. $\mathrm{F}=R$. 'Fen Zhenzhu'; $\mathrm{Z}=R$. 'Zhuangyuan Hong'; $1=0.4 \mathrm{kPa} ; 2=0.99 \mathrm{kPa} ; 3=1.66 \mathrm{kPa}$; $4=2.32 \mathrm{kPa} ; 5=2.98 \mathrm{kPa} ; 6=3.64 \mathrm{kPa}$.
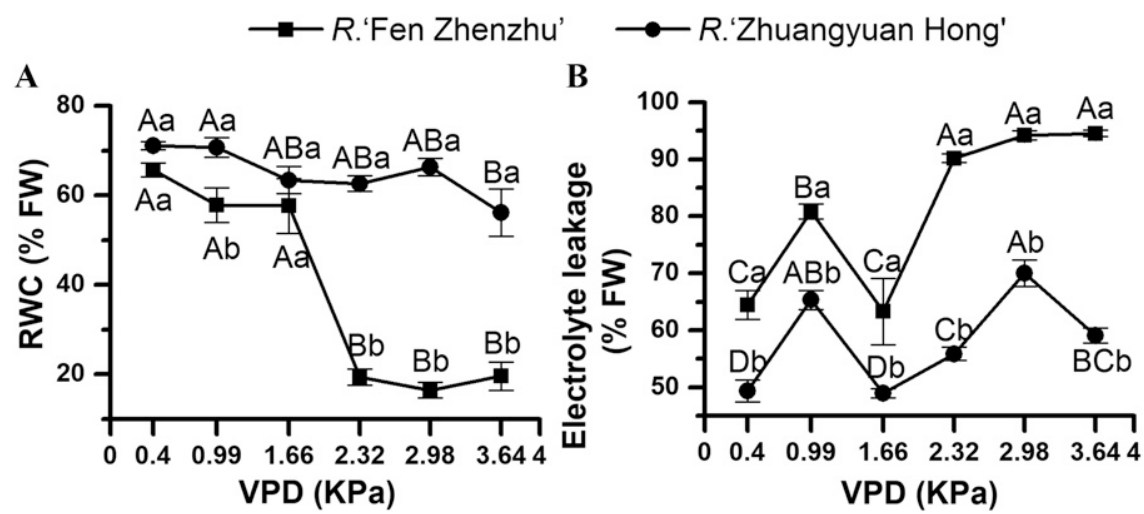

Fig. 2. Effects of different vapor pressure deficits (VPD) on (A) relative water content (RWC) and (B) electrolyte leakage of two Rhododendron cultivars. Different lowercase letters indicate significant differences between $R$. 'Fen Zhenzhu' and $R$. 'Zhuangyuan Hong' at the same relative air humidity, and different uppercase letters indicate significant differences between treatments of the same Rhododendron cultivar by the least significant difference at $P \leq 0.05$.

cultivars under different VPD. After heat stress, both the Rhododendron cultivars suffered effects compared with the control plants, such as water loss, crinkling, desiccation, and abscission of leaves (Fig. 1). Plants also showed different appearances under different RH treatments. The least damage on the appearance of $R$. 'Fen Zhenzhu' was under $75 \% \mathrm{RH}$ in a VPD of $1.66 \mathrm{kPa}$, which showed that about one-half of the leaves etiolated and about one-third of the leaves showed water loss. The most serious damage on the appearance of $R$. 'Fen Zhenzhu' was under $45 \% \mathrm{RH}$ in a VPD of $3.64 \mathrm{kPa}$, which showed that about four-fifths of the leaves etiolated and more than one-half of the leaves dried up. However, $R$. 'Zhuangyuan Hong' showed better appearance than $R$. 'Fen Zhenzhu' under all treatments. The least damage on the appearance of $R$. 'Zhuangyuan Hong' was under $75 \%$ RH in a VPD of 1.66 $\mathrm{kPa}$, which showed that about one-fifth of the leaves crinkled. The most serious damage on the appearance of $R$. 'Zhuangyuan Hong' was under $45 \% \mathrm{RH}$ in a VPD of $3.64 \mathrm{kPa}$, which almost the whole plant showed water loss, with about one-half of the leaves desiccation and a few leaves dropping.

Accordingly, RWC decreased at different degrees in the two Rhododendron cultivars compared with the control treatment (Fig. 2A). RWC at 45\% RH decreased significantly, whereas RWC under other RH treatments had no significant change in $R$. 'Zhuangyuan Hong'. At the same time, there was a significant decline in RWC under $45 \%$, $55 \%$, and $65 \% \mathrm{RH}$ treatments in $R$. 'Fen Zhenzhu'. There were significant differences between the two Rhododendron cultivars under $45 \%, 55 \%, 65 \%$, and $85 \%$ RH. As seen in Fig. 2A, the RWC of $R$. 'Fen Zhenzhu' declined with the increase in VPD before VPD reached $2.98 \mathrm{kPa}$, and RWC had a slight rise when $\mathrm{VPD}$ reached $3.64 \mathrm{kPa}$ compared with RWC in a VPD of $2.32 \mathrm{kPa}$. The changes differed in $R$. 'Zhuangyuan Hong'; RWC had declined before VPD reached $2.32 \mathrm{kPa}$ with the increase in VPD. RWC also had increased slightly when VPD reached $2.98 \mathrm{kPa}$ compared with RWC in a VPD of $1.66 \mathrm{kPa}$; thereafter, RWC declined in a VPD of $3.64 \mathrm{kPa}$.

Regarding electrolyte leakage, it matched the appearance of each treatment and showed a slight decrease under $75 \% \mathrm{RH}$ treatment, while increasing under the other RH treatments in the two Rhododendron cultivars compared with CK (Fig. 2B). Significant differences were observed in the electrolyte leakage between $R$. 'Fen Zhenzhu' and $R$.
'Zhuangyuan Hong'. The same variation trend, first an increase in electrolyte leakage, then a decrease, followed by an increase again and a minimum of electrolyte leakage at $1.66 \mathrm{kPa}$ VPD, was observed in both $R$. 'Fen Zhenzhu' and $R$. 'Zhuangyuan Hong' before VPD reached $2.98 \mathrm{kPa}$. However, in a VPD of $3.64 \mathrm{kPa}$, electrolyte leakage reached the maximum in $R$. 'Fen Zhenzhu' under $45 \%$ RH treatment (increased by $46.7 \%$ ), whereas it declined in $R$. 'Zhuangyuan Hong'.

Effects of different VPDs on photosynthesis and chlorophyll content in the two Rhododendron cultivars. As shown in Fig. 3A, there were significant reductions of $\mathrm{P}_{\mathrm{n}}$ after different $\mathrm{RH}$ treatments under heat stress. The reduction was the least under $75 \% \mathrm{RH}$ treatment in $R$. 'Fen Zhenzhu' (decreased by $79.8 \%$ ) and under $85 \%$ RH treatment in $R$. 'Zhuangyuan Hong' (decreased by $75.4 \%$ ), which showed that these two treatments had the least effects on photosynthesis. In addition, there were clear differences between the two cultivars under all treatments except in that of the $65 \% \mathrm{RH}$ treatment. In $R$. 'Fen Zhenzhu', $\mathrm{P}_{\mathrm{n}}$ first decreased, then increased, decreased, and increased again and the minimum of $\mathrm{P}_{\mathrm{n}}$ was in a VPD of $2.98 \mathrm{kPa}$ (decreased by $94.3 \%$ ). In $R$. 'Zhuangyuan Hong', $P_{n}$ first decreased and then increased slightly and the minimum of $\mathrm{P}_{\mathrm{n}}$ was also in a VPD of $2.98 \mathrm{kPa}$, decreasing by $83.1 \%$.

The $g_{\mathrm{s}}$ and $\mathrm{T}_{\mathrm{r}}$ decreased significantly compared with $\mathrm{CK}$ (Fig. 3C and D). The similar variation trends in $g_{\mathrm{s}}$ and $\mathrm{T}_{\mathrm{r}}$ could be seen in $R$. 'Fen Zhenzhu', and the reduction was the least in a VPD of $2.32 \mathrm{kPa}$ under $65 \%$ $\mathrm{RH}$ treatment and the highest in a VPD of $0.99 \mathrm{kPa}$ under $85 \% \mathrm{RH}$ treatment. However, there was only a minor difference between the variation trends of $g_{\mathrm{s}}$ and $\mathrm{T}_{\mathrm{r}}$ in $R$ 'Zhuangyuan Hong'. The minimum $g_{\mathrm{s}}$ was in a VPD of $0.99 \mathrm{kPa}$ under $85 \% \mathrm{RH}$ treatment, whereas the minimum $\mathrm{T}_{\mathrm{r}}$ was in a VPD of $2.32 \mathrm{kPa}$ under $65 \% \mathrm{RH}$ treatment in $R$. 'Zhuangyuan Hong'. In addition, there were no significant differences between the two cultivars among the treatments. However, significant increase could be seen in $\mathrm{C}_{\mathrm{i}}$ after different $\mathrm{RH}$ treatments under heat stress compared with $\mathrm{CK}$ and the significant differences were between the two Rhododendron cultivars and not the $\mathrm{CK}$ treatment 
(Fig. 3B). $C_{i}$ peaked at a VPD of $1.66 \mathrm{kPa}$ under $75 \% \mathrm{RH}$ treatment in the two cultivars.

After the treatments, chlorophyll content in the two Rhododendron cultivars decreased by different degrees (Fig. 4). In particular, the variation trends of chlorophyll $\mathrm{a}$, chlorophyll $\mathrm{b}$, and total chlorophyll content were the same in $R$. 'Zhuangyuan Hong', and the reduction was the least in a VPD of $2.32 \mathrm{kPa}$ under $65 \% \mathrm{RH}$ treatment (declined by $26.6 \%, 32.4 \%$, and $28.0 \%$, respectively), whereas the minimum chloro- phyll levels were in a VPD of $0.99 \mathrm{kPa}$ under $85 \%$ RH treatment (declined by $43.2 \%$, $46.5 \%$, and $44.0 \%$, respectively). Regarding chlorophyll a, chlorophyll b, and total chlorophyll content in $R$. 'Fen Zhenzhu', the reduction was the least in a VPD of 0.99 $\mathrm{kPa}$ under $85 \% \mathrm{RH}$ treatment (declined by $15.7 \%, 15.0 \%$, and $15.6 \%$, respectively), whereas the minimum chlorophyll levels were in a VPD of $2.98 \mathrm{kPa}$ under $55 \% \mathrm{RH}$ treatment (declined by $27.4 \%, 28.7 \%$, and $27.7 \%$, respectively). However, there were
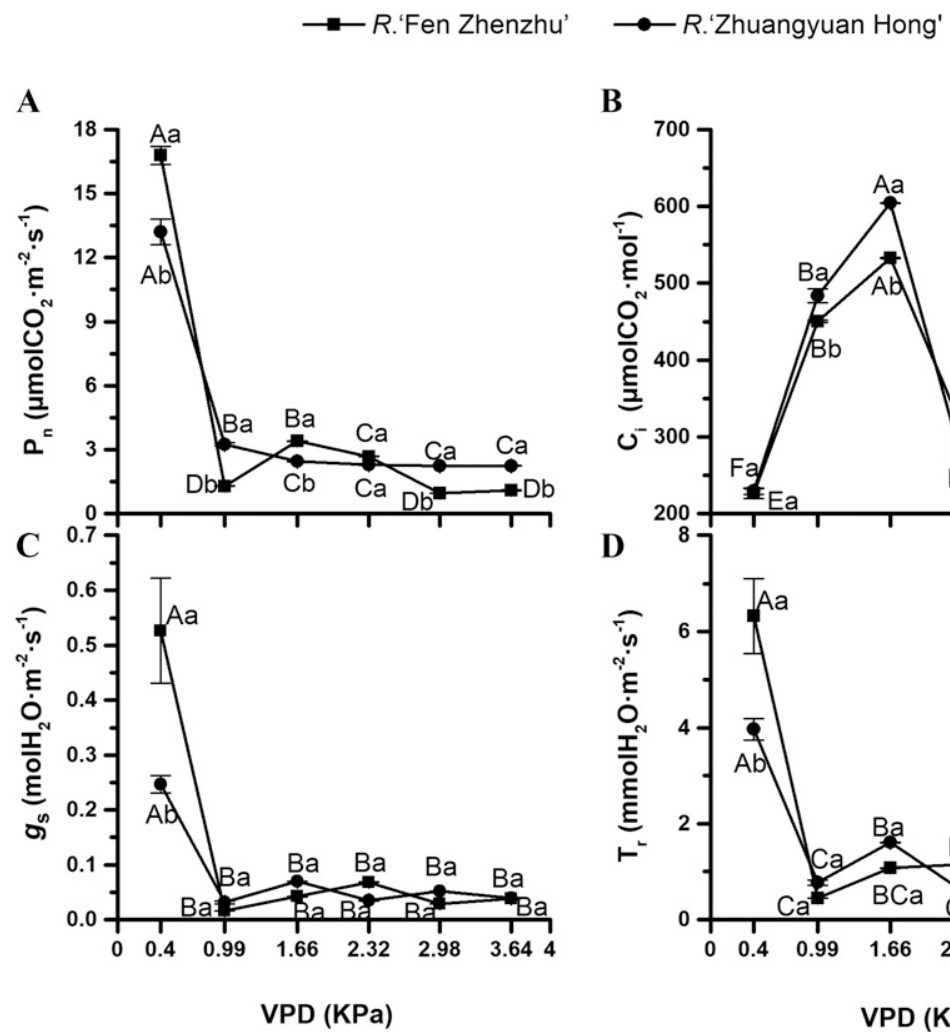

B

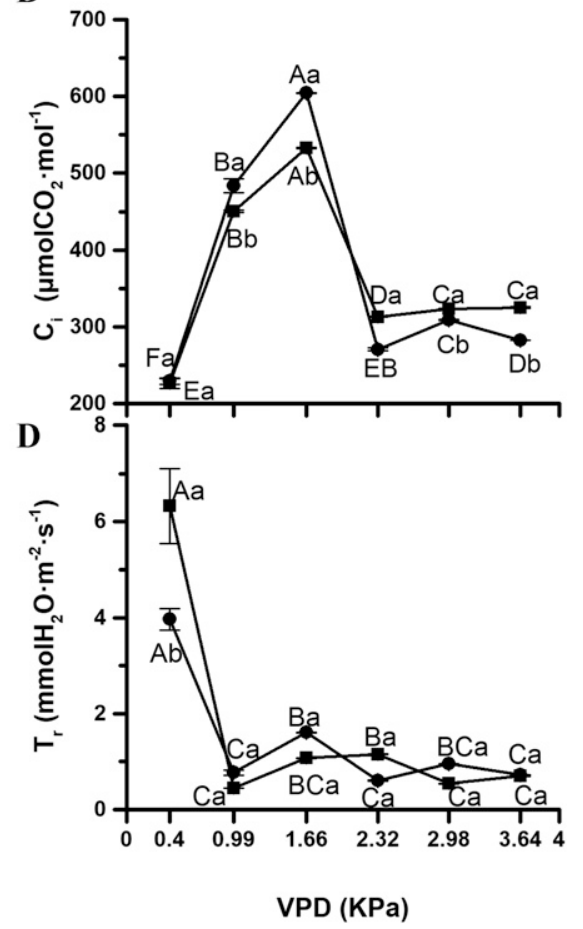

Fig. 3. Effects of different vapor pressure deficits (VPD) on (A) net photosynthetic rate $\left(\mathrm{P}_{\mathrm{n}}\right),(\mathbf{B})$ intercellular CO2 concentration $\left(\mathrm{C}_{\mathrm{i}}\right),(\mathbf{C})$ stomatal conductance $\left(g_{\mathrm{s}}\right)$, and $(\mathbf{D})$ transpiration rate $\left(\mathrm{T}_{\mathrm{r}}\right)$ of two Rhododendron cultivars. Different lowercase letters indicate significant differences between $R$. 'Fen Zhenzhu' and $R$. 'Zhuangyuan Hong' at the same relative air humidity, and different uppercase letters indicate significant differences between treatments of the same Rhododendron cultivar by the least significant difference at $P \leq 0.05$. no significant differences between the two cultivars among the treatments.

Effects of different VPD on anatomy in two Rhododendron cultivars. The treatments of different $\mathrm{RH}$ levels under heat stress significantly affected stomatal density, which reached a maximum at $0.99 \mathrm{kPa}$ VPD under $85 \%$ RH treatment in $R$. 'Fen Zhenzhu', and the reduction was the least at $1.66 \mathrm{kPa}$ VPD under $75 \% \mathrm{RH}$ treatment in $R$. 'Zhuangyuan Hong' (Figs. 5 and 6A). The least reduction of opened stomata ratio and highest increase of stomatal area were at $3.64 \mathrm{kPa}$ in both of two Rhododendron cultivars (Fig. 6B and C), and the minimum was at $0.99 \mathrm{kPa}$ VPD under $85 \%$ RH treatment in $R$. 'Fen Zhenzhu'. In addition, the minimum of opened stomata ratio was at $2.98 \mathrm{kPa} \mathrm{VPD}$ under $55 \% \mathrm{RH}$ treatment and the minimum of stomatal area was at $0.4 \mathrm{kPa}$ VPD in $R$. 'Zhuangyuan Hong'. Thickness of leaves, cuticle, palisade tissue, and midrib were measured and calculated from 15 observations (Fig. 7). The trends in variation of cuticle thickness/leaf thickness were the same between the two Rhododendron cultivars, whereas VPD was over $0.99 \mathrm{kPa}$, and in a VPD of $3.64 \mathrm{kPa}$ under $45 \% \mathrm{RH}$ treatment the ratio of cuticle and leaf thickness reached the highest (Fig. 8A). There were no obvious differences of cell tense ratio and spongy ratio among treatments in $R$. 'Zhuangyuan Hong' (Fig. 8B and $\mathrm{C}$ ). However, in $R$. 'Fen Zhenzhu', the minimum cell tense ratio was in a VPD of $0.99 \mathrm{kPa}$ under the $85 \% \mathrm{RH}$ treatment, whereas the minimum spongy ratio was in a VPD of $3.64 \mathrm{kPa}$ under the $45 \% \mathrm{RH}$ treatment. The ratio of palisade and spongy tissue was the lowest value after $85 \%$ RH treatment in the two Rhododendron cultivars, and the maximum ratios of palisade and spongy tissue were observed under $45 \%$ and $55 \%$ RH in $R$. 'Fen Zhenzhu' and $R$. 'Zhuangyuan Hong', respectively (Fig. 8D).

Effects of different VPD on osmoregulation substances in the two Rhododendron cultivars. Content of osmoregulation substances, such as proline, soluble protein, and soluble sugars, increased under RH treatments in the two Rhododendron cultivars compared with CK
A

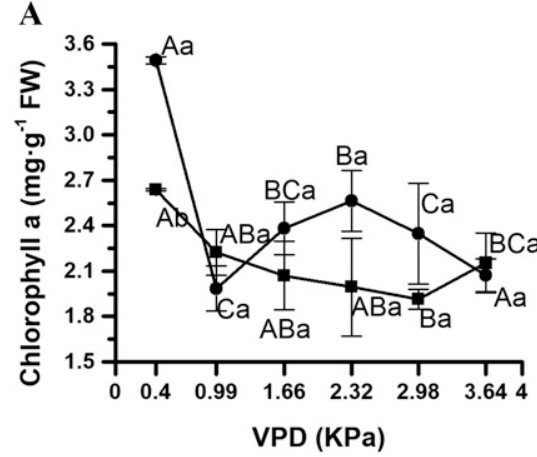

$\longrightarrow$ - .'Fen Zhenzhu' $\bullet-R$.'Zhuangyuan Hong'

B

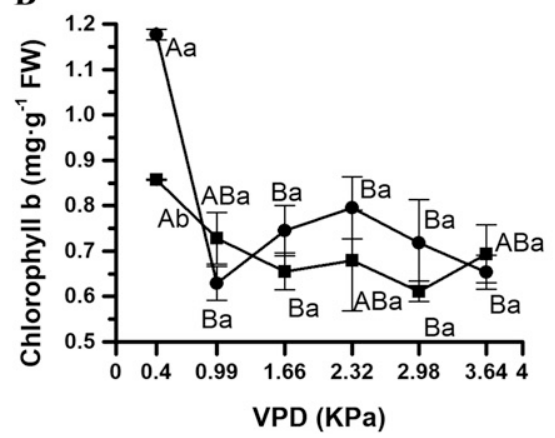

C

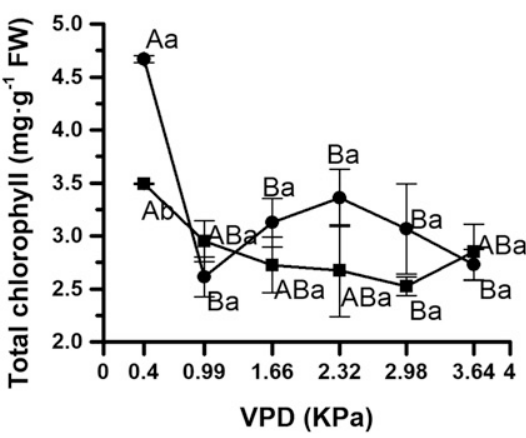

Fig. 4. Effects of different vapor pressure deficits (VPD) on contents of (A) chlorophyll a, (B) chlorophyll b, and (C) total chlorophyll of two Rhododendron cultivars. Different lowercase letters indicate significant differences between $R$. 'Fen Zhenzhu' and $R$. 'Zhuangyuan Hong' at the same relative air humidity, and different uppercase letters indicate significant differences between treatments of the same Rhododendron cultivar by the least significant difference at $P \leq 0.05$. 

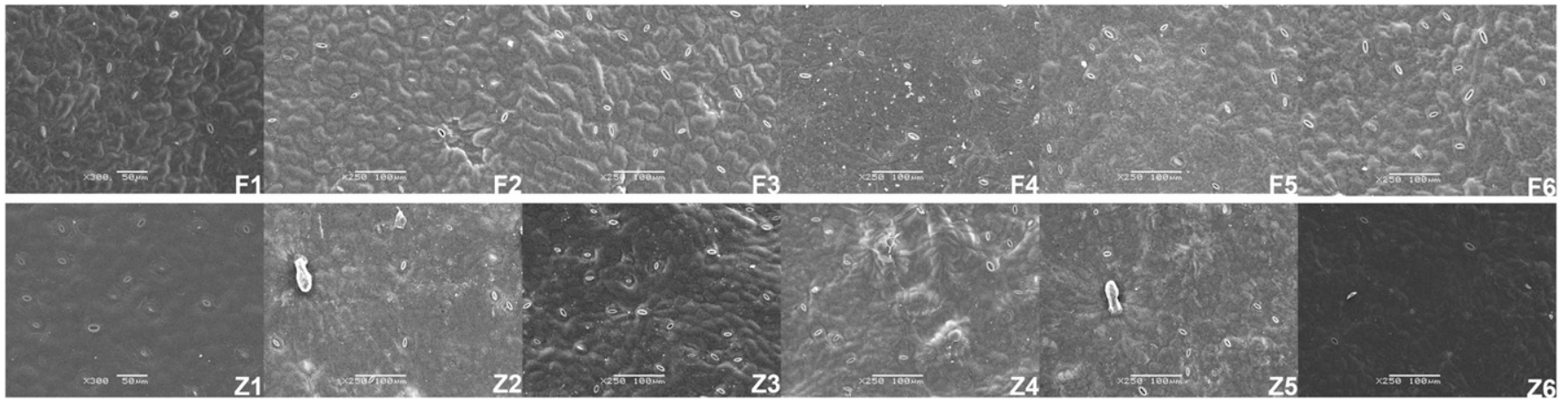

Fig. 5. Effects of different vapor pressure deficits on anatomy of stomata of two Rhododendron cultivars. $\mathrm{F}=R$. 'Fen Zhenzhu'; $\mathrm{Z}=R$. 'Zhuangyuan Hong'; $1=$ $0.4 \mathrm{kPa} ; 2=0.99 \mathrm{kPa} ; 3=1.66 \mathrm{kPa} ; 4=2.32 \mathrm{kPa} ; 5=2.98 \mathrm{kPa} ; 6=3.64 \mathrm{kPa}$.
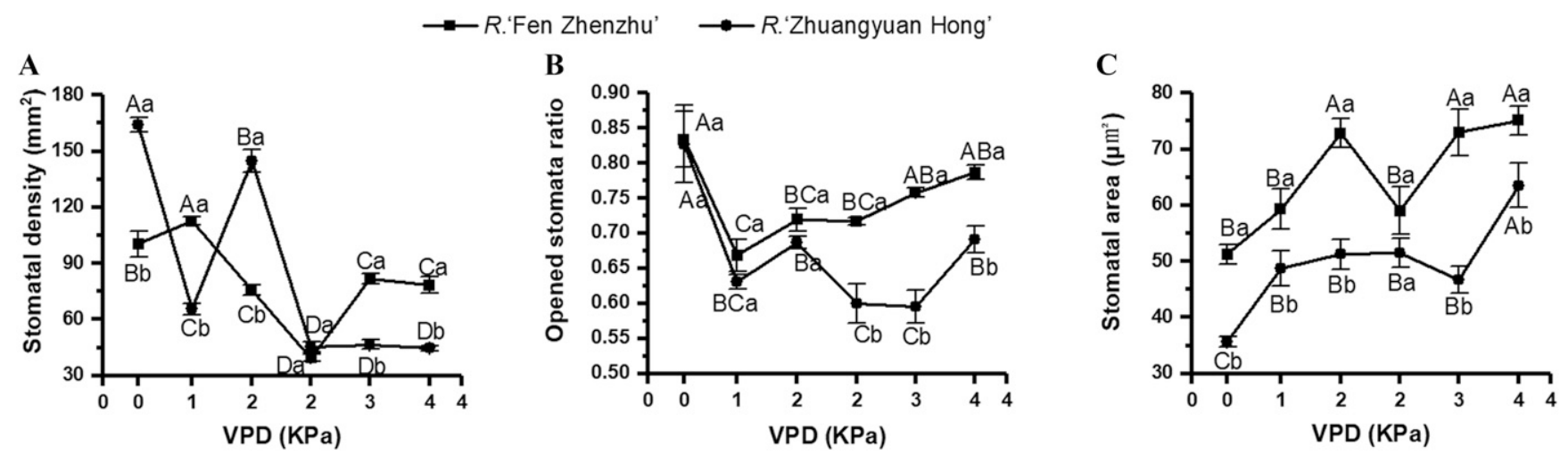

Fig. 6. Effects of different vapor pressure deficits (VPD) on (A) stomata density, (B) opened stomata ratio, and (C) stomatal area of two Rhododendron cultivars. Stomatal density and ratio of opened stomata (the ratio of the average number of open stomata and the average total number of stomata under eight views) were calculated by eight views of scanning electron microscope observations. Fifteen opened stomata lengths and widths were averaged to estimate the stomatal area according to the ellipse area formula: $1 / 4 \times($ length $\times$ width $\times \pi)$. Different lowercase letters indicate significant differences between $R$. 'Fen Zhenzhu' and $R$. 'Zhuangyuan Hong' at the same relative air humidity, and different uppercase letters indicate significant differences between treatments of the same Rhododendron cultivar by the least significant difference at $P \leq 0.05$.
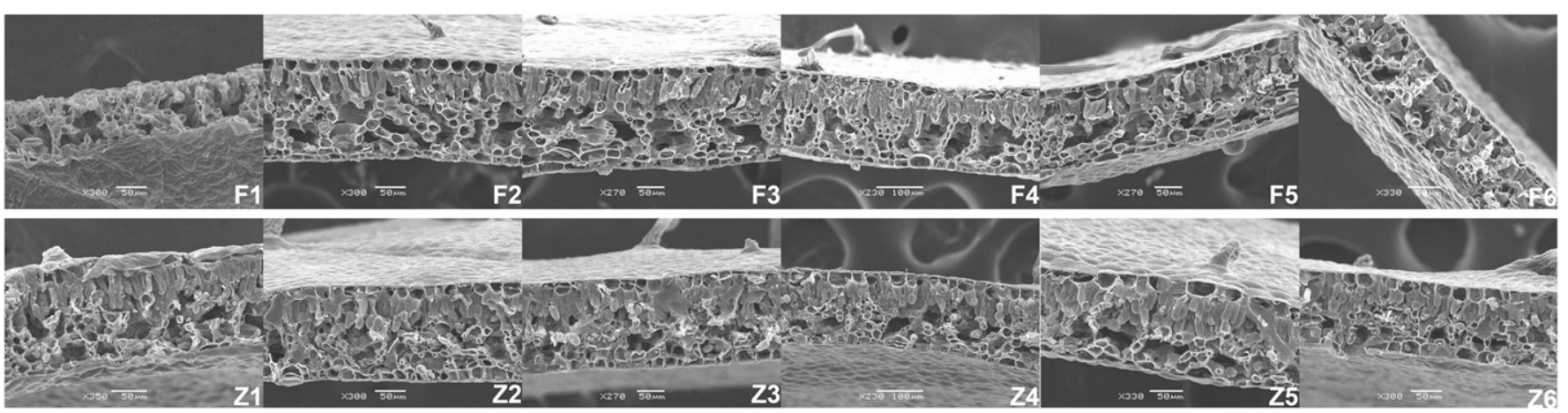

Fig. 7. Effects of different vapor pressure deficits on anatomy of leaves of two Rhododendron cultivars. $\mathrm{F}=R$. 'Fen Zhenzhu'; $\mathrm{Z}=R$. 'Zhuangyuan Hong'; $1=$ $0.4 \mathrm{kPa} ; 2=0.99 \mathrm{kPa} ; 3=1.66 \mathrm{kPa} ; 4=2.32 \mathrm{kPa} ; 5=2.98 \mathrm{kPa} ; 6=3.64 \mathrm{kPa}$.

(Fig. 9). Soluble sugars content fluctuated in $R$. 'Fen Zhenzhu' and the maximum was at a VPD of $3.64 \mathrm{kPa}$ under $45 \% \mathrm{RH}$ treatment in $R$. 'Fen Zhenzhu' (increased by 4.5 times), whereas it was the maximum at a VPD of $1.66 \mathrm{kPa}$ under $75 \% \mathrm{RH}$ treatment in $R$. 'Zhuangyuan Hong' (increased by $81.0 \%$ ). Significant differences in soluble sugars content were observed under $45 \%, 55 \%$, and $65 \% \mathrm{RH}$ treatments between the two cultivars. With the increase in VPD, soluble protein content in $R$. 'Zhuangyuan Hong' increased. In $R$.
'Fen Zhenzhu' the maximum increase $(4.8$ times) was observed at a VPD of $1.66 \mathrm{kPa}$ under $75 \% \mathrm{RH}$ treatment and the minimum (3.3 times) was at a VPD of $2.32 \mathrm{kPa}$ under $65 \% \mathrm{RH}$ treatment. The maximum increase of proline content was observed at a VPD of $3.64 \mathrm{kPa}$ under $45 \% \mathrm{RH}$ treatment in $R$. 'Fen Zhenzhu' and $R$. 'Zhuangyuan Hong' (increased by 3.0 and 1.4 times, respectively), whereas the minimum was at a VPD of $1.66 \mathrm{kPa}$ under $75 \% \mathrm{RH}$ treatment (increased by $88.0 \%$ and $47.7 \%$, respectively).
Effects of different VPDs on ROS and ROS scavenging system in the two Rhododendron cultivars. The two indices that reveal the oxidative stress that tissues undergo are $\mathrm{H}_{2} \mathrm{O}_{2}$ and MDA. With the increase in VPD, $\mathrm{H}_{2} \mathrm{O}_{2}$ content accumulated and achieved the maximum at $0.99 \mathrm{kPa}$ VPD under $85 \%$ RH treatment in $R$. 'Fen Zhenzhu', and the increase was the least at $2.32 \mathrm{kPa}$ VPD under $65 \% \mathrm{RH}$ treatment. In $R$. 'Zhuangyuan Hong', $\mathrm{H}_{2} \mathrm{O}_{2}$ content declined at $0.99 \mathrm{kPa}, 2.98 \mathrm{kPa}$, and $3.64 \mathrm{kPa} \mathrm{VPD}$ and achieved the minimum at $3.64 \mathrm{kPa}$ VPD 
under $45 \%$ RH treatment (Fig. 10A). MDA content was increased under all treatments in the two Rhododendron cultivars. There were only minor differences among treatments in $R$. 'Zhuangyuan Hong'. The maximum was observed at $3.64 \mathrm{kPa}$ VPD and under $45 \% \mathrm{RH}$ treatment in $R$. 'Fen Zhenzhu' (Fig. 10B).

In the ROS scavenging system, the response of the activities of the three antioxidant enzymes to the stress was different from each other (Fig. 11). The activity of SOD exhibited no significant changes and a slight reduction in each treatment in $R$. 'Fen Zhenzhu', and significant changes occurred under heat stress in $R$. 'Zhuangyuan Hong' compared with the control. With the increase in VPD, SOD activity in $R$. 'Zhuangyuan Hong' reduced to the lowest level at $1.66 \mathrm{kPa}$ VPD under $75 \% \mathrm{RH}$ treatment, and then increased. Furthermore, there were significant differences between the two cultivars. Regarding POD activity in $R$. 'Fen Zhenzhu',

it reached the maximum at $1.66 \mathrm{kPa} \mathrm{VPD}$ under $75 \% \mathrm{RH}$ treatment and reduced to the lowest level at $2.98 \mathrm{kPa}$ VPD under $55 \% \mathrm{RH}$ treatment. At the same time, the variation trend of POD activity in $R$. 'Zhuangyuan Hong' was fluctuated and POD activity reached lower levels at $1.66 \mathrm{kPa}$ and 2.98 $\mathrm{kPa} \mathrm{VPD}$ and greater levels at $0.99 \mathrm{kPa}, 2.32$ $\mathrm{kPa}$, and $3.64 \mathrm{kPa}$ VPD. In the variation trends of CAT activity, the maximum was at $2.98 \mathrm{kPa}$ VPD under $55 \% \mathrm{RH}$ treatment and the least increase was at $1.66 \mathrm{kPa} \mathrm{VPD}$ under 75\% RH treatment in $R$. 'Fen Zhenzhu'; however, while the maximum was in the same treatment as in $R$. 'Fen Zhenzhu', the least increase was observed at $0.99 \mathrm{kPa}$ VPD under $85 \% \mathrm{RH}$ treatment in $R$. 'Zhuangyuan Hong'. There were significant differences between the two cultivars.

\section{Discussion}

Effects of RH and high temperature on the anatomical structure of two Rhododendron cultivars. Mortensen and Gislerød (2005) found that when the $\mathrm{RH}$ levels were high under the mild temperature, the responsiveness of stoma decreased. In current study, high RH under high temperature also impaired the responsiveness of stoma. The $g_{\mathrm{s}}$ and $\mathrm{T}_{\mathrm{r}}$ in the two Rhododendron cultivars at $85 \% \mathrm{RH}$ under $38{ }^{\circ} \mathrm{C}$ in a VPD of $0.99 \mathrm{kPa}$ decreased significantly compared with $\mathrm{CK}$, which was treated at $85 \% \mathrm{RH}$ under $22{ }^{\circ} \mathrm{C}$ in a VPD of $0.4 \mathrm{kPa}$ (Fig. 3C and D). Similarly, Zhu and Zhang (2017) pointed that the $g_{\mathrm{s}}$ and $\mathrm{T}_{\mathrm{r}}$ of leaves decreased when the temperature and humidity exceeded the critical value. Furthermore, Yang et al. (2011) believed that with the increase of stress degree, the leaf activity would be inhibited, which was consistent with our research results: the RWC, total chlorophyll, and opened stomata ratio declined in the two Rhododendron cultivars at greater temperature $\left(38^{\circ} \mathrm{C}\right)$ under the same RH (85\%) (Figs. 2A, 4C, and 6B). However, changing $\mathrm{RH}$ under heat stress could alleviate damage of Rhododendron plants caused by high temperature $\left(38^{\circ} \mathrm{C}\right)$. In current study,

Fig. 8. Effects of different vapor pressure deficits (VPD) on (A) the ratio of cuticle thickness and leave thickness, (B) cell tense ratio (CTR), (C) spongy ratio (SR), and (D) the ratio of palisade and spongy thickness of two Rhododendron cultivars. Different lowercase letters indicate significant differences between $R$. 'Fen Zhenzhu' and $R$. 'Zhuangyuan Hong' at the same relative air humidity, and different uppercase letters indicate significant differences between treatments of the same Rhododendron cultivar by the least significant difference at $P \leq 0.05$.

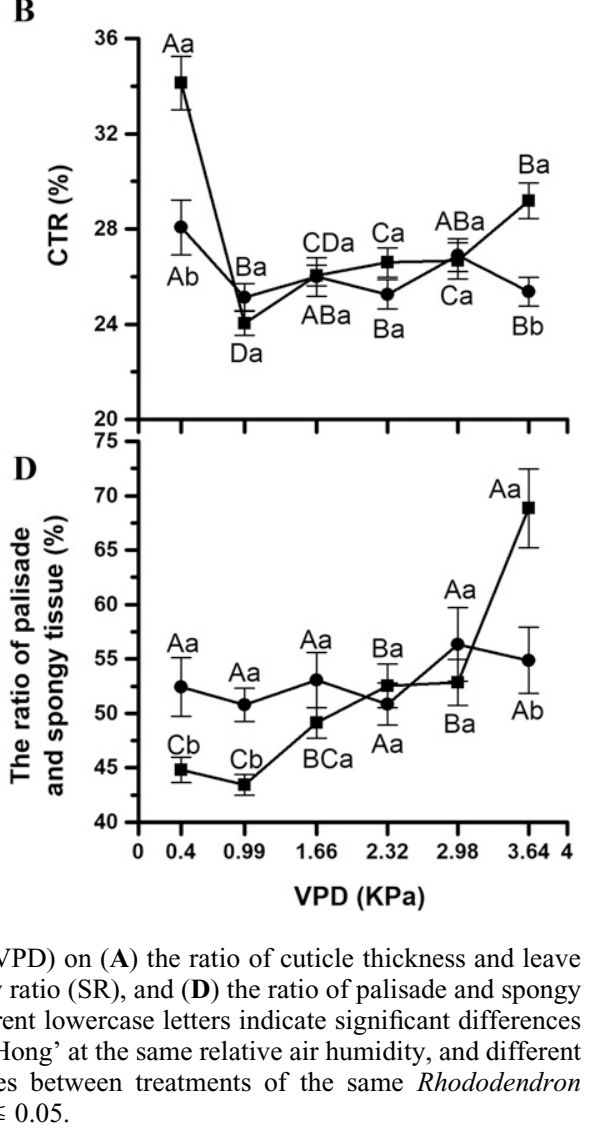

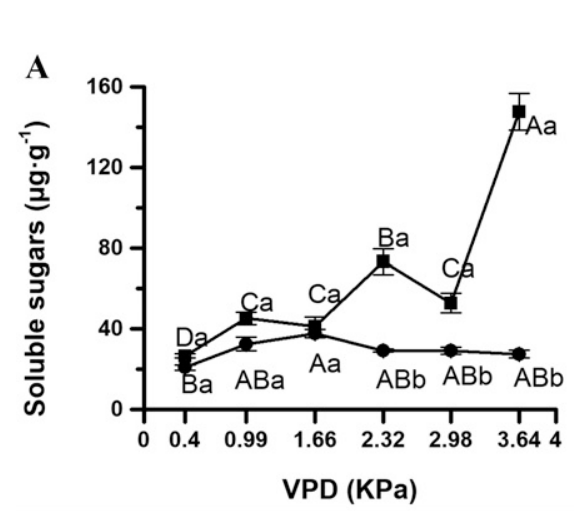
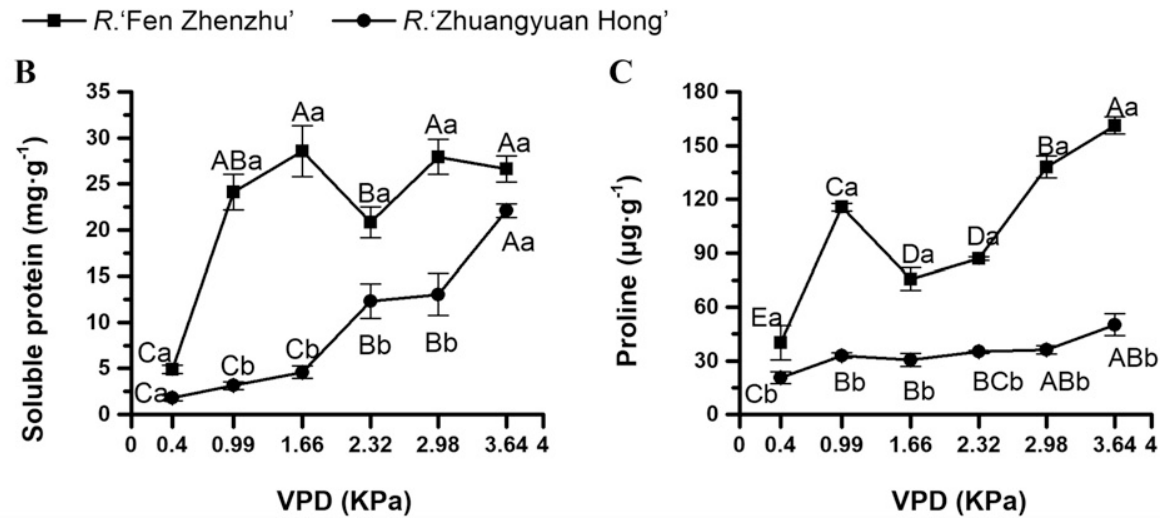

Fig. 9. Effects of different vapor pressure deficits (VPD) on contents of (A) soluble sugars, (B) soluble protein, and (C) proline of two Rhododendron cultivars. Different lowercase letters indicate significant differences between $R$. 'Fen Zhenzhu' and $R$. 'Zhuangyuan Hong' at the same relative air humidity, and different uppercase letters indicate significant differences between treatments of the same Rhododendron cultivar by the least significant difference at $P \leq 0.05$. 
the minimum $\mathrm{T}_{\mathrm{r}}$ was in a VPD of $0.99 \mathrm{kPa}$ under $85 \% \mathrm{RH}$ in the two Rhododendron cultivars (Fig. 3D). Similarly, Giday et al. (2013) found that high RH resulted in a significantly decline of $\mathrm{T}_{\mathrm{r}}$. It may be that the high $\mathrm{RH}(85 \%)$ resulted in reduced stomatal area (Fanourakis et al., 2013) and stomatal responsiveness to closing signals increased stomatal density (Torre et al., 2003). Similarly, stomatal area decline was observed from low $\mathrm{RH}(45 \%)$ to high $\mathrm{RH}$ $(85 \%)$ in the two Rhododendron cultivars (Fig. 6C). The stomata density was the maximum in a VPD of $0.99 \mathrm{kPa}$ under $85 \%$ RH in $R$. 'Zhuangyuan Hong' (Fig. 6A). Furthermore, at the microstructure level of Rhododendron leaves, the ratio of cuticle thickness and leaf thickness was lower under $75 \%$ and $85 \% \mathrm{RH}$ (resulting in a VPD of 1.66 $\mathrm{kPa}$ and $0.99 \mathrm{kPa}$, respectively) than under $45 \%$ and $55 \% \mathrm{RH}$ (resulting in a VPD of 3.64 $\mathrm{kPa}$ and $2.98 \mathrm{kPa}$, respectively) in the two Rhododendron cultivars (Figs. 7 and 8), which probably was because there was more water (greater RWC) stored in the leaves, leaf thickness was greater, or thinner cuticle was generated under the moist atmosphere (great- er RH). Similarly, Giday et al. (2015) found that leaves grown at high RH were larger and thinner, which also increased the $T_{r}$ and facilitated nutrient uptake (Cramer et al., 2009).

Effects of RH and high temperature on the morphology characteristics of two Rhododendron cultivars. It is well known that the growth performance of leaves could be directly damaged by heat stress, which show wilting, curling, chlorosis, and desiccation, even abscission (Sehgal et al., 2017). Damage also was seen in the present study, and plants exhibited different damage under different VPD levels, caused by the change in RH under high temperature (Fig. 1). Compared with $R$. 'Zhuangyuan Hong', $R$. 'Fen Zhenzhu' was clearly vulnerable to heat stress. Under $45 \%$ and $55 \%$ RH treatments (resulting in a VPD of $3.64 \mathrm{kPa}$ and $2.98 \mathrm{kPa}$, respectively), RWC declined more and most of the leaves exhibited wilting, chlorosis, and desiccation in $R$. 'Fen Zhenzhu', whereas leaves of $R$. 'Zhuangyuan Hong' had greater RWC and showed only wilting, which indirectly indicated that $R$. 'Zhuangyuan Hong' had the better ability of conserving water at
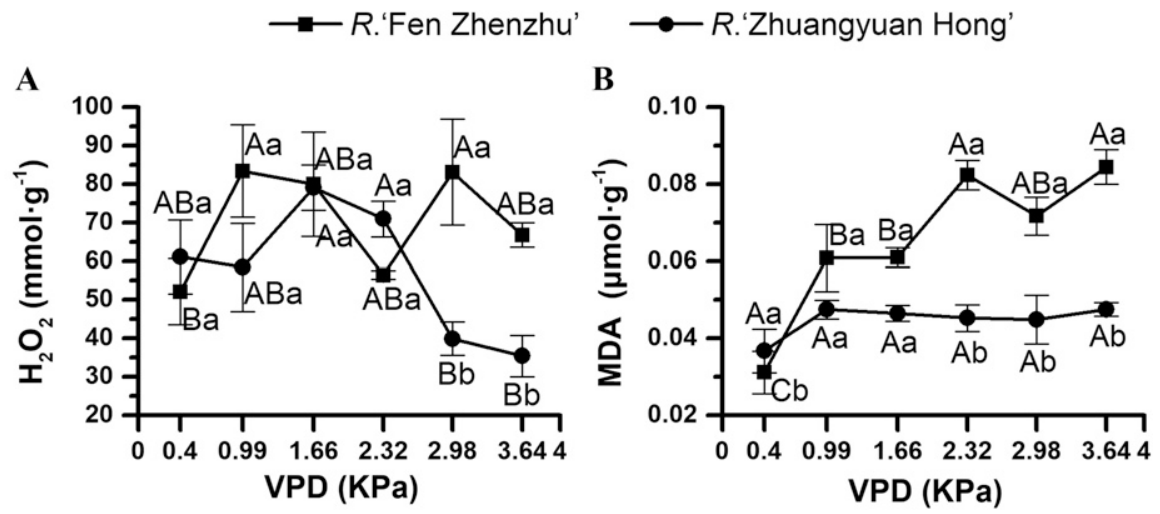

Fig. 10. Effects of different vapor pressure deficits (VPD) on contents of (A) hydrogen peroxide $\left(\mathrm{H}_{2} \mathrm{O}_{2}\right)$, and (B) malondialdehyde (MDA) of two Rhododendron cultivars. Different lowercase letters indicate significant differences between $R$. 'Fen Zhenzhu' and $R$. 'Zhuangyuan Hong' at the same relative air humidity, and different uppercase letters indicate significant differences between treatments of the same Rhododendron cultivar by the least significant difference at $P \leq 0.05$.

low RH under heat stress. Mittler et al. (2012) suggested that plants could activate a process named "programmed cell death" that could cause exfoliation of leaves, sterility of flower, abortion of fruit formation, or even death of the whole plant, to prevent heat stress damage. To some extent, the performance of the plants was related to water loss, and greater $\mathrm{RH}$ could lower water loss and improve RWC (Carvalho et al., 2016). RWC declined less and accordingly, the leaves of Rhododendron suffered less damage at greater RH $(85 \%$, resulting in a VPD of $0.99 \mathrm{kPa})$ in the two Rhododendron cultivars, which was in accordance with Jeon et al. (2006). Furthermore, Giday et al. (2015) found that leaves of plants grown at high $(85 \%) \mathrm{RH}$ were cooler (by 2.2 to $6.9^{\circ} \mathrm{C}$ ) than air temperature. The low leaf temperature might help plants reduce the damage of heat stress. The combined results of growth performance and RWC indicated that greater RH under high temperature had less damage to plants.

Effects of RH and high temperature on the physiology response of two Rhododendron cultivars. Under adverse environments, plants suffer cellular hyperosmolarity and ion disequilibrium. To combat these negative effects, a key regulatory mechanism in many plants is the accumulation of certain organic compounds, generally defined as compatible osmolytes (Yuan et al., 2011). In this experiment, soluble sugar, soluble protein, and proline all increased but in different degrees in each treatment. Their accumulation was beneficial in addressing the reduced water potential and oxidative damage caused by heat stress (Zou et al., 2016). Plants under greater $\mathrm{RH}(75 \%$ and $85 \%$, resulting in a VPD of $2.98 \mathrm{kPa}$ and $3.64 \mathrm{kPa}$, respectively) treatments and even lower RH treatments relied on the common accumulation of soluble sugar, soluble protein, and proline to regulate osmosis and resist heat stress in $R$. 'Fen Zhenzhu'. The accumulation of proline contributed to the maintenance of leaf water content; in addition, soluble sugar has been considered to maintain leaf turgor and participate in the scavenging of oxidative

\section{$\rightarrow-R . ' F e n$ Zhenzhu' $\longrightarrow R$.'Zhuangyuan Hong'}
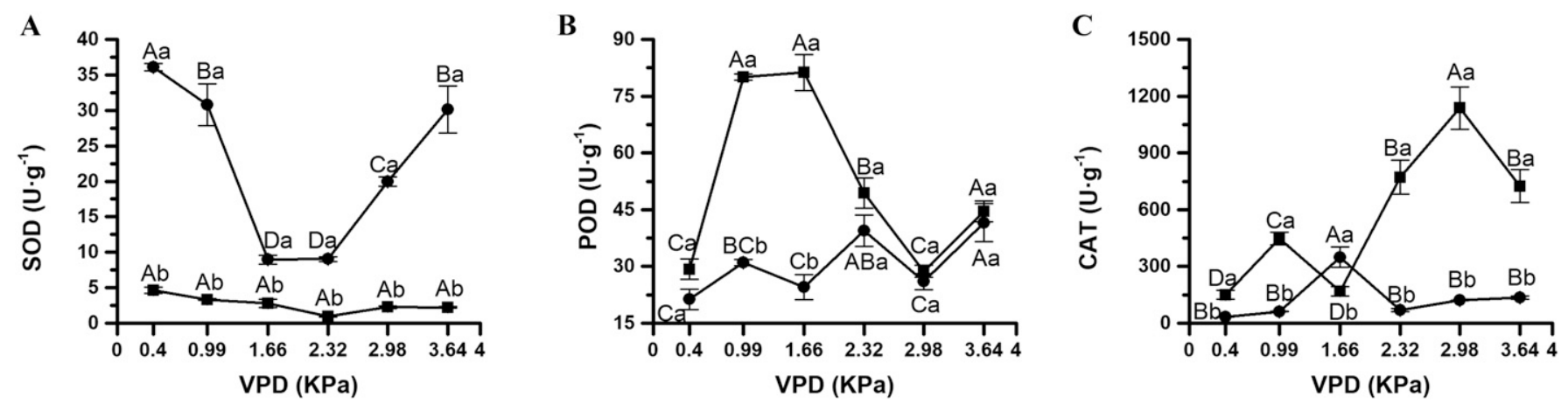

Fig. 11. Effects of different vapor pressure deficits (VPD) on activity of (A) superoxide dismutase (SOD), (B) peroxidase (POD), and (C) catalase (CAT) of two Rhododendron cultivars. Different lowercase letters indicate significant differences between $R$. 'Fen Zhenzhu' and $R$. 'Zhuangyuan Hong' at the same relative air humidity, and different uppercase letters indicate significant differences between treatments of the same Rhododendron cultivar by the least significant difference at $P \leq 0.05$. 
damage, partly due to the activation of specific ROS scavenging systems (Zou et al., 2016). However, the accumulation of soluble sugar and proline were the main osmoregulation substances at $75 \% \mathrm{RH}$, whereas proline mainly regulated osmosis at $85 \% \mathrm{RH}$ in $R$. 'Zhuangyuan Hong'. These results also revealed that there were different responding mechanisms under various $\mathrm{RH}$ treatments in two cultivars.

Electrolyte leakage has been widely defined as a key indicator to assess cell membrane stability (Wang et al., 2017), which results in protein denaturation, enzyme inactivation, and can also impair carbohydrate and protein synthesis and degradation (Patriyawaty et al., 2018; Shen et al., 2017). The electrolyte leakage in response to $75 \%$ RH treatment was not significantly different to $\mathrm{CK}$ in two cultivars, which showed that $75 \% \mathrm{RH}$ had less effects on cellular membranes under heat stress. MDA, an index of the level of lipid peroxidation, can damage membrane integrity and increase membrane permeability (Li et al., 2017). The results also showed that $75 \%$ and $85 \% \mathrm{RH}$ can reduce damage of the cellular membrane by decreasing the content of MDA in $R$. 'Fen Zhenzhu'. Nevertheless, there were no obvious differences in the content of MDA among all treatments in $R$. 'Zhuangyuan Hong', and it could be because the level of decomposition of polyunsaturated and lipid peroxidation was not high. Furthermore, $\mathrm{H}_{2} \mathrm{O}_{2}$ accumulation has been reported to disrupt metabolic function and cellular integrity, cause oxidative damage and weakening cell membrane stability (Imahori et al., 2016). The enzymatic antioxidant system can scavenge $\mathrm{H}_{2} \mathrm{O}_{2}$ and other ROS and thus decrease damage to the cell. In this study, the lowest level of the content of $\mathrm{H}_{2} \mathrm{O}_{2}$ in $R$. 'Zhuangyuan Hong' was seen under $45 \% \mathrm{RH}$, probably because under this treatment $\mathrm{H}_{2} \mathrm{O}_{2}$ specific scavenging enzymes had a greater activity level, like POD. The lowest level of the content of $\mathrm{H}_{2} \mathrm{O}_{2}$ in $R$. 'Fen Zhenzhu' was seen under $65 \% \mathrm{RH}$, at the same time, the activity of SOD reduced to the lowest level under 65\% RH. Similarly, Shen et al. (2017) believed that SOD converts superoxide into $\mathrm{H}_{2} \mathrm{O}_{2}$ to defend against ROS, and then $\mathrm{H}_{2} \mathrm{O}_{2}$ must be further scavenged by POD and CAT.

High temperature disturbs the subtle balance between photosynthesis and respiration; photosynthesis is viewed as a heat-sensitive cell function and process (Yamori et al., 2014). The structure and function of the chloroplasts are disturbed, photosynthetic pigments are degraded, and the photosystem II and the activation state of rubisco are influenced under high temperature (Sang et al., 2017; Sharwood et al., 2017). Leaves lose their green color and are not able to perform photosynthesis. The least reduction in the $\mathrm{P}_{\mathrm{n}}$ was observed under greater $\mathrm{RH}$ ( $75 \%$ in $R$. 'Fen Zhenzhu' and $85 \%$ in $R$. 'Zhuangyuan Hong'), whereas a marked decrease was observed under high temperature stress. Photosynthetic pigment is closely related with $\mathrm{P}_{\mathrm{n}}$. However, total chlorophyll content was not the greatest when $P_{n}$ achieved the maximum in two cultivars under heat stress. It is also known that photosynthesis decreases through stomatal and/or nonstomatal limitations (Perdomo et al., 2016). The decreased $\mathrm{P}_{\mathrm{n}}$ observed may have not been due to increased stomatal limitation, since the results were observed that $C_{i}$ increased and $T_{r}$ decreased under heat stress treatments. Stomatal conductance showed opposite changes to respond to $\mathrm{C}_{\mathrm{i}}$ during heat stress, which suggested that non-stomatal limitations worked. In addition, the $T_{r}$ was related to stomatal area, stomatal density, and opened stomata ratio. Under $75 \% \mathrm{RH}$ in $R$. 'Zhuangyuan Hong', the reduction of the $\mathrm{T}_{\mathrm{r}}$ was the least. At the same time, the reduction in stomatal density was also the least and the reduction of opened stomata ratio was still lower, and the stomatal area was not the greatest. In addition, there was nearly the same situation under $65 \% \mathrm{RH}$ in $R$. 'Fen Zhenzhu'. It can be inferred that the reduction of $\mathrm{P}_{\mathrm{n}}$ under different $\mathrm{RH}$ treatments was the combined influence of photosynthetic pigment, gas exchange, and opening and closing of stomata.

In conclusion, the present study demonstrated that changing $\mathrm{RH}$ under heat stress can alleviate damage of Rhododendron plants caused by high temperature and to some extent greater RH results in less damage. Under greater $\mathrm{RH}$, plants can avoid damage by increasing photosynthesis and photosynthetic pigments, adjusting opening and closing of stomata, enhancing enzymatic activity and osmotic adjustment, and improving leaf structure. However, it would be necessary to understand that even under the same treatments the effects of RH under heat stress in the two Rhododendron cultivars was different. After treatments, $R$. 'Zhuangyuan Hong' showed less damage and better thermostability than $R$. 'Fen Zhenzhu'. In summary, damage of Rhododendron and other ornamental plants caused by heat stress can be alleviated through regulating other environmental factors, like $\mathrm{RH}$ and reduced energy consumption, and is of vital significance in the management of Rhododendron in landscaping.

\section{Literature Cited}

Arve, L.E., O.M.O. Kruse, K.K. Tanino, J.E. Olsen, C. Futsather, and S. Torre. 2017. Daily changes in VPD during leaf development in high air humidity increase the stomatal responsiveness to darkness and dry air. J. Plant Physiol. 211:63-69.

Barrs, H.D. and P.E. Weatherley. 1962. A reexamination of the relative turgidity techniques for estimating water deficits in leaves. Austral. J. Biol. Sci. 15:413-428.

Bates, L.E., R.P. Waldren, and I.D. Teare. 1973. Rapid determination of free proline for water stress studies. Plant Soil 39:205-207.

Carvalho, D.R.A., M.W. Vasconcelos, S. Lee, C.F.S. Koning-Boucoiran, D. Vreugdenhil, F.A. Krens, E. Heuvelink, and S.M.P. Carvalho. 2016. Gene expression and physiological responses associated to stomatal functioning in Rosa $\times$ hybrida grown at high relative air humidity. Plant Sci. 253:154-163.
Chance, B. and A.C. Maehly. 1955. Assay of catalase and peroxidases. Methods Enzymol. 11:764-775.

Chen, W.L., W.J. Yang, H.F. Lo, and D.M. Yeh. 2014. Physiology, anatomy, and cell membrane thermostability selection of leafy radish (Raphanus sativus var. oleiformis Pers.) with different tolerance under heat stress. Scientia Hort. 179:367-375.

Cramer, M., H.J. Hawkins, and G.A. Verboom. 2009. The importance of nutritional regulation of plant water flux. Oecologia 161:15-24.

Fanourakis, D., R. Pieruschka, A. Savvides, A.J. Macnish, V. Sarlikioti, and E.J. Woltering. 2013. Sources of vase life variation in cut roses: A review. Postharvest Biol. Technol. 78:1-15.

Fanourakis, D., A.I. Velez-Ramirez, B.-C. In, H. Barendse, U. van Meeteren, and E.J. Woltering. 2015. A survey of preharvest conditions affecting the regulation of water loss during vase life. Acta Hort. 1064:195-204.

Fanourakis, D., D. Bouranis, H. Giday, D.R.A. Carvalho, A.R. Nejad, and C. Ottosen. 2016. Improving stomatal functioning at elevated growth air humidity: A review. J. Plant Physiol. 207:51-60.

Giannopolitis, C.N. and S.K. Ries. 1977. Superoxide dismutases: I. Occurrence in higher plants. Plant Physiol. 59:309-314.

Giday, H., K.H. Kjaer, D. Fanourakis, and C.-O. Ottosen. 2013. Smaller stomata require less severe leaf drying to close: A case study in Rosa hydrida. J. Plant Physiol. 170:1309-1316.

Giday, H., K.H. Kjaer, D. Fanourakis, and C.-O. Ottosen. 2015. Cultivar differences in plant transpiration rate at high air humidity are not related to genotypic variation in stomatal responsiveness. Acta Hort. 1064:99-106.

Haupt, M., M. Weigl, M. Grabner, and T. Boettger. 2011. A 400-year reconstruction of July relative air humidity for the Vienna region (eastern Austria) based on carbon and oxygen stable isotope ratios in tree-ring latewood cellulose of oaks (Quercus petraea Matt. Liebl.). Clim. Change 105:243-262.

Hiscox, J.T. and G. Israelstam. 1979. A method for the extraction of chlorophyll from leaf tissue without maceration. Can. J. Bot. 57:13321334.

Howell, T.A. and D.A. Dusek. 1995. Comparison of vapor-pressure-deficit calculation methods Southern High Plains. J. Irrig. Drain. Eng. 121:191-198.

Imahori, Y., J. Bai, and E. Baldwin. 2016. Antioxidative responses of ripe tomato fruit to postharvest chilling and heating treatments. Scientia Hort. 198:398-406.

Irigoyen, J.J., D.W. Emerich, and M. Sanchez-diaz. 1992. Water stress induced changes in the concentrations of proline and total soluble sugars in nodulated alfalfa (Medicago sativa) plants. Physiol. Plant. 8:455-460.

Jeon, M.W., M.B. Ali, E.J. Hahn, and K.Y. Paek. 2006. Photosynthetic pigments, morphology and leaf gas exchange during ex vitro acclimatization of micropropagated CAM Doritaenopsis plantlets under relative humidity and air temperature. Environ. Exp. Bot. 55:183-194.

Li, N., F.M. Chen, F.J. Cui, W.J. Sun, J.S. Zhang, L.S. Qian, Y. Yang, D. Wu, Y. Dong, J.X. Jiang, and H.P. Yang. 2017. Improved postharvest quality and respiratory activity of straw mushroom (Volvariella volvacea) with ultrasound treatment and controlled relative humidity. Scientia Hort. 225:56-64.

Lu, T., Z.J. Meng, G.X. Zhang, M.F. Qi, Z.P. Sun, Y.F. Liu, and T.L. Li. 2017. Sub-high temperature and high light intensity induced irreversible 
inhibition on photosynthesis system of tomato plant (Solanum lycopersicum L.). Front. Plant Sci. 08:365.

Marchin, R.M., A.A. Broadhead, L.E. Bostic, R.R. Dunn, and W.A. Hoffmann. 2016. Stomatal acclimation to vapor pressure deficit doubles transpiration of small tree seedlings with warming. Plant Cell Environ. 39:2221-2234.

Martin, C. and J.C. Stutz. 2004. Interactive effects of temperature and arbuscular mycorrhizal fungi on growth, $\mathrm{P}$ uptake and root respiration of Capsicum annuum L. Mycorrhiza 14:241244.

Mittler, R., A. Finka, and P. Goloubinoff. 2012. How do plants feel the heat? Trends Biochem. Sci. 37(3):118-125.

Mortensen, L.M. and H.R. Gislerød. 2005. Effect of air humidity variation on powdery mildew and keeping quality of cut roses. Scientia Hort. 104:49-55.

Mueller, S.P., D.M. Krause, M.J. Mueller, and A. Fekete. 2015. Accumulation of extrachloroplastic triacylglycerols in Arabidopsis seedlings during heat acclimation. J. Expt. Bot. 66:4517-4526.

New, M., D. Lister, M. Hulme, and I. Makin. 2002. A high-resolution data set of surface climate over global land areas. Clim. Res. 21:1-25.

Ohama, N., H. Sato, K. Shinozaki, and K. YamaguchiShinozaki. 2017. Transcriptional regulatory network of plant heat stress response. Trends Plant Sci. 22:53-65

Palta, J.P., J. Levitt, and E. Stadelman. 1977. Freezing injury in onion bulb cells. I. Evaluation of the conductivity method and analysis of ion and sugar efflux from injured cells. Plant Physiol. 60:393-397.

Patriyawaty, N.R., R.C.N. Rachaputi, D. George, and C. Douglas. 2018. Genotypic variability for tolerance to high temperature stress at reproductive phase in Mungbean [Vigna radiata (L.) Wilczek]. Scientia Hort. 227:132-141.

Perdomo, J.A., E. Carmosilva, C. Hermidacarrera, J. Flexas, and J. Galmes. 2016. Acclimation of biochemical and diffusive components of photosynthesis in rice, wheat, and maize to heat and water deficit: Implications for modeling photosynthesis. Front. Plant Sci. 7:1719.

Pereira, G.J.G., S.M.G. Molina, P.J. Lea, and R.A. Azevedo. 2002. Activity of antioxidant enzymes in response to cadmium in Crotalaria juncea. Plant Soil 239:123-132.

Sang, Q.Q., X. Shan, Y.H. An, S. Shu, J. Sun, and S.R. Guo. 2017. Proteomic analysis reveals the positive effect of Exogenous Spermidine in tomato seedlings' response to high-temperature stress. Front. Plant Sci. 8:120.

Sehgal, A., K. Sita, J. Kumar, S. Kumar, S. Singh, K.H.M. Siddique, and H. And Nayyar. 2017. Effects of drought, heat and their interaction on the growth, yield and photosynthetic function of lentil (Lens culinaris Medikus) genotypes varying in heat and drought sensitivity. Front. Plant Sci. 8:1776.

Sharwood, R.E., K.Y. Crous, S.M. Whitney, D.S. Ellsworth, and O. Ghannoum. 2017. Linking photosynthesis and leaf $\mathrm{N}$ allocation under future elevated $\mathrm{CO}_{2}$ and climate warming in Eucalyptus globulus. J. Expt. Bot. 68:11571167.

Shen, H.F., B. Zhao, J.J. Xu, W. Liang, W.M. Huang, and H.H. Li. 2017. Effects of heat stress on changes in physiology and anatomy in two cultivars of Rhododendron. S. Afr. J. Bot. 112:338-345.

Shen, H.F., B. Zhao, J.J. Xu, X.Z. Zheng, and W.M. Huang. 2016. Effects of salicylic acid and calcium chloride on heat tolerance in Rhododendron 'Fen Zhen Zhu'. J. Amer. Soc. Hort Sci. 141:363-372.

Sinclair, T., E. Fiscus, B. Wherley, M. Durham, and T. Rufty. 2007. Atmospheric vapor pressure deficit is critical in predicting growth response of "cool-season" grass Festuca arundinacea to temperature change. Planta 227: 273-276.

Torre, S., T. Fjeld, H.R. Gislerød, and R. Moe. 2003. Leaf anatomy and stomatal morphology of greenhouse roses grown at moderate or high air humidity. J. Amer. Soc. Hort. Sci. 128:598 602.

Tullus, A., P. Kupper, A. Sellin, L. Parts, J. Sober, T. Tullus, K. Lohmus, A. Sober, and H. Tullus. 2012. Climate change at northern latitudes: Rising atmospheric humidity decreases transpiration, N-Uptake and growth rate of hybrid aspen. PLoS One 7(8):e42648.

Wang, J., P. Burgess, S.A. Bonos, W.A. Meyer, and B. Huang. 2017. Differential physiological responses and genetic variations in fine fescue species for heat and drought stress. J. Amer. Soc. Hort. Sci. 142:367-375.

Wang, R.H., Y. Mei, L. Xu, X.W. Zhu, Y. Wang, J. Guo, and L.W. Liu. 2018. Differential proteomic analysis reveals sequential heat stressresponsive regulatory network in radish (Raphanus sativus L.) taproot. Planta 247:11091122.
Yamori, W., K. Hikosaka, and D.A. Way. 2014. Temperature response of photosynthesis in C-3, C-4, and CAM plants: Temperature acclimation and temperature adaptation. Photosynth. Res. 119:101-117.

Yan, X.H., F. Lv, C.J. Liu, and Y.F. Zheng. 2010. Selection and characterization of a hightemperature tolerant strain of Porphyra haitanensis Chang et Zheng (Bangiales, Rhodophyta). J. Appl. Phycol. 22:511-516.

Yang, A.L., Z.Y. Cheng, Y.L. Xue, J. Sun, and Y.X. Li. 2011. Temperature and humidity regulation for autumn prolonging cultivation facility grape in zhangye city. J. Shanxi Agricul. Sci. 39(2):136-139 (in Chinese).

Yu, K.D., K.L. Zhu, M.J. Ye, Y.P. Zhao, W.R. Chen, and W.D. Guo. 2016. Heat tolerance of highbush blueberry is related to the antioxidative enzymes and oxidative protein repairing enzymes. Scientia Hort. 198:36-43.

Yuan, Y., H.M. Qian, Y.D. Yu, F.Q. Lian, and D.Q. Tang. 2011. Thermotolerance and antioxidant response induced by heat acclimation in Freesia seedlings. Acta Physiol. Plant. 33:10011009.

Zhang, J., D.M. Li, W.J. Sun, X.J. Wang, and B.J. Gang. 2012. Exogenous phydroxybenzoic acid regulates antioxidant enzyme activity and mitigates heat stress of cucumber leaves. Scientia Hort. 148:235-245.

Zhang, M.X., G.J. Zhang, Y.H. You, C.Q. Yang, P.M. Li, and F.W. Ma. 2016. Effects of relative air humidity on the phenolic compounds contents and coloration in the 'Fuji' apple (Malus domestica Borkh.) peel. Scientia Hort. 201:18 23.

Zhou, W.J. and M. Leul. 1998. Uniconazoleinduced alleviation of freezing injury in relation to changes in hormonal balance, enzyme activities and lipid peroxidation in winter rape. Plant Growth Regulat. 26:41-47.

Zhu, Y.Q. and Z.Q. Yang. 2017. Effect of high temperature and high humidity on stomatal and photosynthesis characteristics of grape leaves in greenhouse. Nor Horticul. 23:94-101 (in Chinese).

Zou, M.Q., L.Y. Yuan, S.D. Zhu, S. Liu, J.T. Ge, and C.G. Wang. 2016. Response of osmotic adjustment and ascorbate-glutathione cycle to heat stress in a heat-sensitive and a heattolerant genotype of wucai (Brassica campestris L.). Scientia Hort. 211:87-94. 